\title{
STUDIES ON PHOTORESISTS DERIVED FROM SI CYCLIZED COPOLYMERS
}

\author{
Yu Shangxian Li Lin Gu Jiangnan \\ Su Cuihua Wang Jiliang \\ Chemistry Department of Beijing Normal University \\ No.19 Xinjiekouwai Beijing, China, 100875
}

\begin{abstract}
A series of styrene-isoprene copolymers (SI copolymers) have been synthesized from styrene and isoprene. The styreneisoprene cyclized copolymers (SI cyclized copolymers) have been synthesized by proper cyclization of the obtained copolymers. Through the regulation of ether additives, the copolymers contain different 1,4-copolymer content and 3,4-copolymer content. The relative content of 3,4-copolymer and 1,4-copolymer in SI copolymers is calculated by data of IR and ${ }^{1} \mathbf{H}$ NMR spectra and the cyclization process is monitored by IR spectra. In this paper, we discuss the influence of various factors on the copolymerization, the cyclization and the products in detail. The minimum quantity of exposure energy required $\mathbf{E}_{\min }$ of the photoresists prepared by SI cyclized copolymers is about $9.7 \mathrm{~mJ} / \mathrm{cm}^{2}$. The resistance of the photoresist to acids and plasma etching is better than that of cyclized polyisoprene photoresist.
\end{abstract}

\section{Introduction}

The synthesis of styrene - isoprene copolymer by random or block copolymerization of styrene and isoprene has been reported in many papers ${ }^{[1]}$. Yet in previous studies, the SI copolymer was usually studied for use as rubber materials, and their further cyclization and modification were never involved, let alone be used as photoresist.

This paper reports the synthesis of SI cyclized copolymer by proper cyclization of SI copolymer obtained from isoprene and styrene under acidic condition, as shown in general chemical reaction formula 1 and 2:

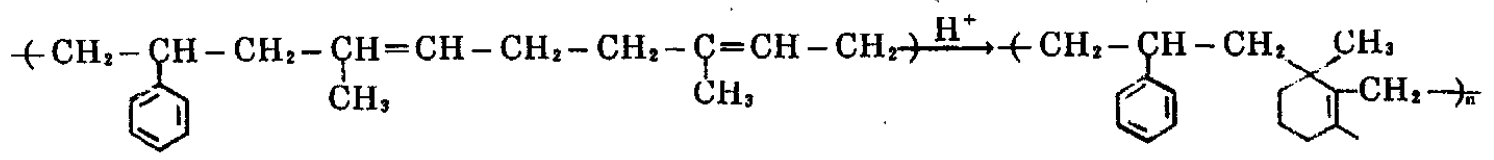




$$
+\mathrm{CH}_{2}-\underset{\mathrm{CH}_{2}}{\mathrm{C}}-\mathrm{CH}_{\mathrm{CH}_{2}}^{\mathrm{CH}}-\mathrm{CH}_{2}-\underset{\mathrm{CH}_{3}}{\mathrm{CH}}+\mathrm{CH}_{3}^{+}
$$

Since this kind of cyclized copolymer contains high density of benzene rings, so the negative photoresist prepared from it and crosslinking agent $\mathrm{BAC}-\mathrm{M}$ not only has the advantages of cyclized polyisoprene photoresist, but also has better resistance to some acids, alkali and plasma etching.

\section{Experimental}

\subsection{Polymerization and cyclization}

A series of copolymerized reactions were carried out as follows. The amount of solvent, reactants and additive were shown in Table 1.

Table 1 The amount of solvent, reactants and additive in copolymerization

\begin{tabular}{|c|c|c|c|c|c|c|c|c|c|c|c|c|c|c|c|c|c|c|c|c|}
\hline No. & 1 & 2 & 3 & 4 & 5 & 6 & 7 & 8 & 9 & 10 & 11 & 12 & 13 & 14 & 15 & 16 & 17 & 18 & 19 & 20 \\
\hline xylene $(\mathrm{g})$ & 360 & 360 & 360 & 360 & 360 & 360 & 360 & 360 & 360 & 360 & 360 & 360 & 360 & 360 & 360 & 360 & 360 & 360 & 360 & 360 \\
\hline styrene(g) & 2 & 6 & 10 & 14 & 20 & 2 & 6 & 10 & 14 & 20 & 2 & 6 & 10 & 14 & 20 & 2 & 6 & 10 & 14 & 20 \\
\hline isoprene(g) & 38 & 34 & 30 & 26 & 20 & 38 & 34 & 30 & 26 & 20 & 38 & 34 & 30 & 26 & 20 & 38 & 34 & 30 & 26 & 20 \\
\hline THF(ml) & 0 & 0 & 0 & 0 & 0 & 0.06 & 0.06 & 0.06 & 0.06 & 0.06 & 0.15 & 0.15 & 0.15 & 0.15 & 0.15 & 0.29 & 0.29 & 0.29 & 0.290 .29 \\
\hline
\end{tabular}

A flask was heated and vacuum-pumped. After it was cooled, xylene was poured into it through a syringe needle by the press of $\mathrm{N}_{2}$. placed the flask in $50^{\circ} \mathrm{C}$ oil bath and then poured styrene into it. After impurities were consumed, isoprene monomer was added and polymerized reaction was initiatied by $\mathrm{n}-\mathrm{BuLi}$ with remarkable self-exothermic process and viscosity increasing. After self-exothermic process alleviated, the flask was still maintained $50^{\circ} \mathrm{C}$ with shaking for 1 hour. Then add terminator to stop the reaction. Pour all the liquid in the flask into large amount of $\mathrm{MeOH}$ and the product was precipitated. After drying, the semi-transparent copolymer with proper elasticity and rigidity was obtained.

The above SI copolymer was dissolved in xylene to accurately prepared a solution with proper concentration. Using tuluenesulfonic acid as catalyst, under different conditions cyclized reaction was carried out with stirring for several hours using $\mathrm{N}_{2}$ protection. After drying, a transparent light-yellow solution containing SI cyclized copolymer obtained. The product was recovered by filtration and precipitation in $\mathrm{MeOH}$.

2.2. Determination and calculation of synthesized products by infrared spec- 
trophotometry and ${ }^{1} \mathrm{H}$ NMR spectroscopy

To determine and analyze the compositions and structures of the products, IR spectra and ${ }^{1} H$ NMR spcetra were measured by Shimazu IR -408 spectrometer and JAMPMAX 60 spectrometer respectively.

The obtained SI copolymers contain three kinds of copolymers: 1,4-copolymer, 1,2 -copolymer and 3,4-copolymer. In this paper we mainly discuss 1,4 -copolymer and 3,4 - copolymer.

The ratio of 3,4 -copolymer content to 1,4 -copolymer content is calculated by formula 3 using data of IR spectrum:

$$
\frac{3,4-\text { copolymer content }}{1,4-\text { copolymer content }}=\frac{\mathrm{d}_{830}}{\mathrm{~d}_{890}} \cdot \frac{\varepsilon_{890}}{\varepsilon_{830}}
$$

In formula $3 \mathrm{~d}_{830}$ and $\mathrm{d}_{890}$ are absorbances of the absorption bands at $830 \mathrm{~cm}^{-1}$ and 890 $\mathrm{cm}^{-1}$ which associated with double bonds in 3,4-copolymer and 1,4-copolymer respectively. $\varepsilon_{830}$ and $\varepsilon_{890}$ are their corresponding molar absorptivities. The details are discussed in references [2] and [3].

In 'H NMR spectrum the chemical shifts of double bonds protons of 1,4-copolymer and 3,4-copolymer are at $\delta=5.05$ and $\delta=4.66$ respectiv ely $^{[4]}$. Given $\mathrm{A}$ and $\mathrm{B}$ are integrations at $\delta=5.05$ and $\delta=4.66$ respectively, then $1,4-$ copolymer content $\mathrm{C}_{1,4} \%$ and 3,4 -copolymer content $\mathrm{C}_{3,4} \%$ are calculated by formula 4 and 5 .

$$
\begin{aligned}
& \mathrm{C}_{1,4} \%=\frac{\mathrm{A}}{\mathrm{A}+\frac{1}{2} \mathrm{~B}} \times 100 \% \\
& \mathrm{C}_{3,4} \%=\frac{\frac{1}{2} \mathrm{~B}}{\mathrm{~A}+\frac{1}{2} \mathrm{~B}} \times 100 \%
\end{aligned}
$$

In ${ }^{1} \mathrm{H}$ NMR spectrum of cyclized product the chemical shift of double bond in ring appears at $\delta=5.25$, which shows that cyclization has occured and resulted in SI cyclized copolymer.

In IR spectra of a series of samples obtained during the cyclized process the bands at $890 \mathrm{~cm}^{-1}$ and $830 \mathrm{~cm}^{-1}$ decrease only that at $699 \mathrm{~cm}^{-1}$ is constant during the whole cyclization progress. From this and combining ${ }^{1} \mathbf{H}$ NMR spectrum of uncyclized copolymer the percent of uncyclized isoprene units $\mathbf{P} \%$ may be calculated by formula 6

$$
\mathrm{P} \%=\mathrm{C}_{1,4} \mathrm{P}_{1,4}+\mathrm{C}_{3,4} \mathrm{P}_{3,4}
$$

In formula $6 \mathrm{C}_{1,4}$ and $\mathrm{C}_{3,4}$ are calculated by formula 4 and 5 respectively; $P_{1,4}$ and $P_{3,4}$ are percents of uncyclized 1,4-isoprene units and 3,4-isoprene units 
respectively calculated from the above IR spectra ${ }^{[2]}$. Therefore the cyclization process may be monitored by IR spectra.

2.3. Determination of molecular weight $\overline{\mathbf{M}}_{\mathrm{w}}$, kinematic viscosity, hardness and iodine value

The molecular weight $\overline{\mathbf{M}}_{\mathrm{w}}$ and molecular weight distribution $\mathrm{D}$ were determined by GPC. The kinematic viscosity of the copolymer solution in xylene was determined by kinematic viscosimeter. The hardness was measured by Shore durometer. The iodine value which describes the unsaturated degree was determined by Wijs agent method.

2.4. Photosensitivity and resistance of photoresist prepared by SI cyclized copolymer with photocrosslinking agent

A proper amount of 2,6-bis - (azidobenzal) - 4-methyl-cyclohexanone (BACM) as a photocrosslinking agent was added into solutions of SI cyclized copolymers in xylene and resulted in a kind of negative photoresist.

The photoresist was coated evenly on the aluminum base and after baked at $70^{\circ} \mathrm{C}$ for $30 \mathrm{~min}$, the photoresist film with thickness of $2 \mu \mathrm{m}$ was exposed under UV light using Kodark Photographic Step Tablet No.2 as mask. After the film was developed with xylene, observe and count the residual segments on the tablet and calculate the minimum quantity of exposure energy required $\mathrm{E}_{\min }{ }^{[5]}$.

After exposed and developed, the films coated on the aluminum, stainless steel bases and silicon wafer were placed into some acids to test their resistance. Their resistance to plasma etching was also tested. The resolution of etched images was examined.

\section{Results and Discussion}

3.1. Regularities of polymerization

Previous studies have shown that the difference of active energy is significant during the polymerization process of styrene and isoprene. When ethers are added, this difference will decrease and it will be beneficial to random copolymerization, but the ratio of 3,4 -copolymer content to that of 1,4 -copolymer in obtained copolymer will also change remarkably. The more the additive amount of ethers, the greater the change will be. The above changes initiated by THF as additive are shown in Table 2 . It is quite clear that 3,4 -copolymer content increases with the amount of THF increasing.

Table 2 Influence of amount of THF on 3,4-copolymer content and 1,4-copolymer content

\begin{tabular}{|c|c|c|c|c|}
\hline Number & 2 & 7 & 12 & 17 \\
\hline amount of THF (ml) & 0 & 0.06 & 0.15 & 0.29 \\
\hline$\frac{3,4-\text { copolymer content }}{1,4-\text { copolymer content }}$ & 0.139 & 0.233 & 0.391 & 0.587 \\
\hline
\end{tabular}


Because 1,4-copolymer content and 3,4-copolymer content are different, kinematic viscosities of the copolymers solutions in xylene are also different. From 4 groups of Table 3 it can be seen that kinematic viscosities of copolymers in xylene increase with additive amount of ethers increasing under case of the same molecular weight $\overline{\mathbf{M}}_{\mathbf{w}}$ and molecular weight distribution $\mathrm{D}$.

Table 3 Influence of amount of THF on kinematic viscosity

\begin{tabular}{|c|c|c|c|c|c|c|c|c|}
\hline group & \multicolumn{2}{|c|}{1} & \multicolumn{2}{c|}{2} & \multicolumn{2}{c|}{3} & \multicolumn{2}{c|}{4} \\
\hline No. & 4 & 9 & 14 & 19 & 3 & 8 & 10 & 15 \\
\hline amount of THF (ml) & 0 & 0.06 & 0.15 & 0.29 & 0 & 0.30 & 0.30 & 0.60 \\
\hline $\bar{M}_{\mathrm{w}}$ & $17 \times 10^{4}$ & $17 \times 10^{4}$ & $8.3 \times 10^{4}$ & $8.4 \times 10^{4}$ & $24 \times 10^{4}$ & $24 \times 10^{4}$ & $17 \times 10^{4}$ & $17 \times 10^{4}$ \\
\hline $\mathrm{D}$ & 1.06 & 1.05 & 1.03 & 1.04 & 1.07 & 1.09 & 1.05 & 1.06 \\
\hline kinematic viscosity(Ct) & 60.8 & 66.8 & 22.0 & 28.3 & 162.4 & 196.9 & 50.9 & 54.9 \\
\hline
\end{tabular}

Besides THF, glycol diethyl ether, dioxane and isoamyl ether et al. have also been used as additives. They all have functions of decreasing active energy and regulating structure. The polymerized and cyclized products show the best solubility in the mixed solution formed by xylene and THF, and also in this system the filtration and precipitation of the cyclized product after cyclization process are most convenient.

Just as $\mathrm{n}-\mathrm{BuLi}$ is a fine initiator in polymerization of isoprene, so it is a excellent initiator in the copolymerization of styrene and isoprene. In the overwhelming majority of cases the molecular weight distributions of SI copolymers are 1.04 1.1 and those of SI cyclized copolymers are 1.2 1.3.

Influence of the amount of $n-B u L i$ on molecular weight $\overline{\mathbf{M}}_{\mathbf{w}}$ and kinematic viscosities of the copolymers is in agreement with the regularities shown in polymerization of isoprene.

Influence of molar ratio of styrene to isoprene in the copolymers on molecular weight $\overline{\mathbf{M}}_{\mathrm{w}}$ and molecular weight distribution $\mathrm{D}$ is not significant. But other conditions being equal kinematic viscosity of the copolymers in xylene decreases and hardness increases with styrene content increasing (Table 4).

Table 4 Influence of the ratio of styrene to isoprene on $\bar{M}_{w}, D$, kinematic viscosity and hardness

\begin{tabular}{|c|c|c|c|c|}
\hline S:I (molar ratio) & $1: 29$ & $1: 8.7$ & $1: 2.8$ & $1: 1.5$ \\
\hline kinematic viscosity & 33.2 & 30.2 & 28.3 & 21.2 \\
\hline$\overline{\mathrm{M}}_{\mathrm{w}}$ & $11 \times 10^{4}$ & $10 \times 10^{4}$ & $8 \times 10^{4}$ & $10 \times 10^{4}$ \\
\hline $\mathrm{D}$ & 1.05 & 1.05 & 1.04 & 1.04 \\
\hline hardness (Shore unit) & $<20$ & $<30$ & $50-70$ & $>70$ \\
\hline
\end{tabular}




\subsection{Regularities of cyclization}

In studies of cyclization of polyisoprene, the cyclization process is generally described by percent of uncyclized isoprene units $\mathrm{P} \%$ and degree of cyclization $\mathrm{R} \%$ (Percent of disappeared double bond). The latter is associated with iodine value (1$R$ is in positive proportion to iodine value).From Table 5 it can be seen that when using $3.5 \%$ toluenesulfonic acid as catalyst and reacting at $65^{\circ} \mathrm{C}$ for 4 hours, $\mathrm{P}$ and iodine value decrease more rapidly as the concentration of the copolymer solution in xylene increases. This indicates that the cyclization process proceeds more rapidly.

Table 5 Influence of concentration of the copolymer solution in the cyclization on $P$ and iodine value

\begin{tabular}{|c|c|c|c|c|c|}
\hline concentration \% & 6 & 7 & 8 & 9 & 10 \\
\hline P\% & 69.3 & 66.9 & 50.1 & 38.7 & 16.1 \\
\hline iodine value & 264.2 & 231.9 & 226.7 & 186.7 & - \\
\hline
\end{tabular}

It has been found that the cyclization of polyisoprene proceeds very slowly using $3 \%$ toluenesulfonic acid as catalyst below $70^{\circ} \mathrm{C}$ with $10 \%$ solution of polyisoprene, but the cyclized rate of SI copolymers is much greater under the same conditions. As we can see from Table 6, $\mathrm{P}$ will decrease to below $50 \%$ rather rapidly at $65^{\circ} \mathrm{C}$ after 4 hours of the cyclization. There may be two reasons:

1. The SI copolymers contain benzene ring, so they have better solubility and the solubility of toluenesulfonic acid is also improved, therefor the catalytic effect is promoted.

2. The structure of 3,4-copolymer is in favor of the cyclization process. These inferences have been further confirmed by experimental results in Table 7 and Table 8.

Table 6 P of cyclized products under different temperature (reacting for 4hours)

\begin{tabular}{|c|c|c|c|c|}
\hline copolymer No.7 & $50^{\circ} \mathrm{C}$ & $55^{\circ} \mathrm{C}$ & $60^{\circ} \mathrm{C}$ & $65^{\circ} \mathrm{C}$ \\
\hline $\mathrm{P} \%$ & 97.8 & 88.1 & 66.5 & 49.7 \\
\hline
\end{tabular}

From Table 7, we can see that $\mathbf{P}$ decreases rapidly which means the rate of the cyclization gets much greater under the same conditions as 3,4-copolymer content in SI copolymers increases.

From Table 8 , we can see that in the cyclization of SI copolymer obtained by 
different polymerized ratios of styrene to isoprene, $P$ decreases with considerably high speed as styrene content increases under the same cyclic conditions.

Table $7 \quad \mathrm{P}$ determined after two hours of cyclization of SI copolymers obtained when different amount of THF was added

\begin{tabular}{|c|c|c|c|}
\hline \multirow{2}{*}{$\begin{array}{c}\text { amount of THF } \\
(\mathrm{ml})\end{array}$} & \multicolumn{3}{|c|}{$\mathrm{P} \%$} \\
\cline { 2 - 4 } & at $55^{\circ} \mathrm{C}$ & at $60^{\circ} \mathrm{C}$ & at $65^{\circ} \mathrm{C}$ \\
\hline 0 & 99.3 & 82.8 & 64.7 \\
\hline 0.06 & 88.1 & 66.5 & 49.7 \\
\hline 0.29 & 84.1 & 57.7 & 13.3 \\
\hline
\end{tabular}

Table $8 \quad \mathrm{P}$ determined after the cyclization of SI copolymers of different ratios of styrene to isoprene

\begin{tabular}{|c|c|c|c|c|}
\hline S:I (molar ratio) & polyisoprene & $1: 8.7$ & $1: 2.8$ & $1: 1.5$ \\
\hline P\% & 0.38 & 0.36 & 0.28 & 0.08 \\
\hline
\end{tabular}

As for the influence of the amount of catalyst and the duration of reaction on the cyclization the regularities are basically in agreement with that of the cyclization of polyisoprene. The results are listed in Table 9 and Table 10.

Table 9 Influence of the amount of catalyst on $\mathrm{P}\left(65^{\circ} \mathrm{C}\right.$, 4hours, S:I=1:8.7 $10 \%$ solution of the copolymer)

\begin{tabular}{|c|c|c|c|c|c|}
\hline concentration of catalyst \% & 0 & 1 & 2 & 3 & 4 \\
\hline $\mathrm{P} \%$ & 98.1 & 55.7 & 48.4 & 32.7 & 22.7 \\
\hline
\end{tabular}

Table 10 Influence of the duration of the cyclization on $\mathrm{P}\left(80^{\circ} \mathrm{C}, 3.5 \%\right.$ catalyst, $\mathrm{S}: \mathrm{I}=1: 8.7,10 \%$ solution of the copolymer)

\begin{tabular}{|c|c|c|c|c|}
\hline duration of cyclization(min) & 60 & 75 & 120 & 130 \\
\hline $\mathrm{P} \%$ & 61.8 & 36.4 & 20.4 & 20.8 \\
\hline
\end{tabular}

3.3. Photosensitivity and resistance of the photoresists derived from SI cyclized copolymers and $\mathrm{BAC}-\mathrm{M}$.

Some photocompositions derived from SI cyclized copolymers and 3 5\% BACM can be used as photoresists. The data measured by Kodark Photographic Step Tablet No.2 are shown in Table 11. The minimum quantity of exposure energy required $E_{\min }$ is about $9.7 \mathrm{~mJ} / \mathrm{cm}^{2}$ calculated from those data in Table 11.

Table 11 The data for measurement of $\mathrm{E}_{\min }$ (the exposure power $1.45 \mathrm{~mW} / \mathrm{cm}^{2}$ )

\begin{tabular}{|c|c|c|c|}
\hline exposure time (S) & 30 & 40 & 60 \\
\hline number of residual segments & 5 & 6 & 7 \\
\hline
\end{tabular}


The photocured film on aluminum base was etched by concentrated phosphoric acid at $50^{\circ} \mathrm{C}$ resulting in a complete and clear image with $2 \mu \mathrm{m}$ line width. The photocured film on silicon wafer was etched by etchant composed of $\mathrm{HF}$ and $\mathrm{NH}_{4} \mathrm{~F}$ for $40 \mathrm{~min}$ resulting in roughly complete image. The resistance to this etchant approximates to that of cyclized polyisoprene photoresist. The resistance of plasma etching is also quite nice.

After exposure, development and baking, the stainless steel plates coated with a layer of SI cyclized copolymers photoresists which are derived from different ratios of styrene to isoprene were immered into $12 \mathrm{~N} \mathrm{HCl}$ for $15-45 \mathrm{~min}$. The results indicate that containing a small amount of styrene is good for the photoresists to be more resistant to $\mathrm{HCl}$ etching. The etched images with $2 \sim 3 \mu \mathrm{m}$ line width have relatively steep edges. But when styrene content is rather large, the viscidity of the film of the photoresist decreases, so that the film may completely release into etchant.

\section{4. conclusion}

With the initiation by $\mathrm{n}-\mathrm{BuLi}$, SI copolymers whose molecular weight distribution $\mathrm{D}$ is about 1.1 and molecular weight $\overline{\mathrm{M}}_{\mathrm{w}}$ is appropriate can be synthesized from isoprene and styrene id xylene. The structure of the SI copolymers can be regulated by changing the amount of additive THF. Under the acidic condition, the cyclization rate of the SI copolymers is rather high. Some photosensitive compositions derived from SI cyclized copolymers and 2,6-bi$\mathrm{s}$-(azidobenzal) -4-methyl-cyclohexanone are a kind of satisfied photoresist.

\section{References}

1. G. NATTA. J. polym. Sci. 34, 21 (1959)

2. Li Lin, Yu Shangxian, et al., J. Beijing Normal University (Natural Science), 1993, No.1, P.117- 120

3. W.S. Richardson and A. Sacher, J. Polym. Sci. Vol.10, No.4, P.353-370

4. Ram K· Agnihotri, D. Falcon, et al., J. Polym. Sci. Part A-1, Val.10, 1839-1850 (1972)

5. Nagamatsu et al., Photopolymers P. 55-60, Tokyo, (1978) 